\title{
LA VIDA Y SUS SENTIDOS
}

GUILLERMO HURTADO

INSTTTUTO DE INVESTIGACIONES FILOSÓFICAS

UNIVERSIDAD NACIONAL AUTÓNOMA DE MÉxICO

Cualquiera puede tener alguna vez la sospecha de que la vida es absurda. Uno puede detener el camino y preguntarse: ¿cuál es el sentido de que trabaje horas extra, de que ahorre parte de mi salario, de que le sea fiel a mi pareja, de que vaya a la iglesia el domingo? ¿Cuál es el sentido de que las gentes nazcan, crezcan, se llenen de ilusiones, se enamoren, hagan cosas pequeñas y grandes, entierren a sus seres queridos, pierdan fortuna e ilusiones, envejezcan y mueran? ¿Cuál es el sentido de todo esto que es la vida? Para algunos esta interrogante es una molestia pasajera, inofensiva; para otros, en cambio, se convierte en una obsesión que les quita el sueño. No voy a ofrecer aquí una respuesta a la pregunta por el sentido de la vida. No creo que haya una pregunta y si la hubiera no sabría qué tipo de respuesta podría dársele. Mi propósito se limita a entender las diversas preguntas que nos planteamos cuando nos preocupa el sentido de la vida. En particular deseo señalar la diferencia que hay entre la pregunta por el sentido y la pregunta por el valor de la vida y, también, entre la pregunta por el sentido y el valor de mi vida y la pregunta por el sentido o el valor de la vida. Se trata pues de un punto de partida en vez de uno de llegada - aunque para mí no sea una partida agradable. Escribí este ensayo con la esperanza de poder dejar de pensar en el asunto, pero pronto descubrí que para lograrlo tendría que hacer algo más $\longrightarrow$ quizá algo menos- que escribir sobre el tema.

Hay muchos que afirman sinceramente no entender la pregunta por el sentido de la vida. Esto se debe, en mi opinión, a que hay varios problemas detrás de la pregunta en su formulación habitual. Una manera indirecta - y muy común- de elucidarla es caracterizar como absurda una vida sin sentido. Sin embargo, me parece que no hay un criterio preciso que marque cuándo una circunstancia es absurda. El concepto de lo absurdo acoge en su extensión una familia muy amplia de situaciones afines. Hay distintos tipos de circunstancias que podemos calificar como absurdas, y si bien algunas 
son relevantes para la cuestión acerca del sentido de la vida, otras no lo son. Consideremos algunas de las que nos conciemen. Hay acciones ordinarias y razonables que en algunas circunstancias se vuelven absurdas. Amarrarse las agujetas es algo que hacemos todos los días. Pero imaginemos el siguiente caso. Un hombre está en un paredón de fusilamiento. Segundos antes de que el pelotón dispare, el hombre se agacha para amarrarse las agujetas y luego se vuelve a incorporar para esperar la descarga. Lo que hace absurda la situación anterior es que en esa circunstancia amarrarse las agujetas no cumple con ninguna finalidad inteligible. Hay otro tipo de situaciones absurdas que si bien cumplen con alguna finalidad son inútiles. Imaginemos un trasatlántico que se hunde a la mitad del océano. Un pasajero desesperado saca agua de la cubierta con una pequeña cubeta. A diferencia del caso de las agujetas, la acción del hombre en el barco tiene una finalidad específica: sacar agua del navío. Lo que hace absurda su acción es la dimensión de su inutilidad. Hay otros casos de acciones inútiles que también son absurdas pero que deben distinguirse de las anteriores. Por ejemplo, supongamos que después de un fuerte chubasco un hombre sale al jardín y se pone a regarlo. A diferencia de la anterior, esta situación atenta contra el sentido común de una manera más violenta. Podemos entender la razón por la que el hombre saca agua con la cubeta: está desesperado y quiere evitar el naufragio. Pero no podemos entender que alguien en su pleno juicio riegue sobre mojado. Un ejemplo similar al anterior es el de un hombre que construye una casa con muchos sacrificios y cuando la ve acabada la destruye con una carga de dinamita. Lo que hace absurda a esta situación es su inexplicabilidad, más que su inutilidad.

Hay quienes han visto la totalidad de los actos de nuestra vida como el acto de amarrarse las agujetas en un paredón. Nuestros actos, según esta perspectiva, no cumplen con niguna finalidad porque están hechos al borde de la muerte. Buscar el sentido de la vida es, entonces, buscar alguna finalidad de nuestros actos que no se vea arruinada por la banalidad de las cosas humanas. También se ha visto la totalidad de nuestros actos como el intento desesperado de sacar agua de un trasatlántico averiado. Desde esta perspectiva todo lo que hacemos es inútil porque tarde o temprano todo se convierte en polvo. Buiscar el sentido de la vida sería, entonces, buscar una razón para vivir que no se viera afectada por el hecho ineludible de que en este mundo no hay cosa buena o mala que dure. Hay, incluso, quienes han visto los actos e intenciones de nuestra vida como irracionales, una vez que nos damos cuenta de que el entusiasmo y la esperanza que nos impulsan a vivir son traicionados no sólo por la brevedad y futilidad de las cosas humanas, sino por todas nuestras miserias y bajezas. Una vida así no sólo es absurda, sino patética, carente de todo valor. ¿Qué sentido tiene hacer y 
querer hacer lo que hacemos si todo acaba en la cloaca? ¿No es preferible el suicido a seguir soportando esta farsa cruel?

Ya que son muy pocos los que prefieren el suicidio, la actitud más común es responder que la vida no es una farsa y que aunque lo fuera el suicidio no es la mejor opción. Es en este momento que muchos tratan de encontrar errores en los razonamientos que llevan a concluir que la vida no tiene sentido. Lo que los motiva es la inquebrantable convicción de que la vida no puede ser absurda ya que de serlo sus propias vidas también serían absurdas y, por tanto, tiene que haber alguna falla en el argumento. Debo confesar que yo mismo, cuando he sentido que mi vida está en juego, he buscado errores a diestra y siniestra en los argumentos de los pesimistas y cuando no los he encontrado, he tratado de olvidarme del asunto bebiendo una cerveza, jugando un partido de backgammon. La excusa que doy -que me doy a mí mismo- es que mi reacción es inevitable, aunque esto no implique que no sea a su vez absurda. Para muchos esta reacción es suficiente para rechazar el interrogante acerca del sentido de la vida. El juego de propuestas y objeciones sobre el tema acaba cuando uno de los participantes se siente en peligro y lo corta. Pero como tarde o temprano el diálogo se suspende, el problema del sentido de la vida es en realidad - se nos dice- un pseudo-problema (se recordará que hay un argumento análogo en contra del escepticismo). Siempre he pensado que lo anterior no implica estrictamente que la vida no sea absurda, sólo que si lo es no hay ningún problema genuino al respecto; es decir, ningún problema que pueda dirimirse de una manera racional, de una manera práctica. Sin embargo, me parece que aunque nuestra flaqueza nos impida avanzar en un diálogo sostenido sobre el sentido de la vida, esto no implica que no sea un problema genuino. Sigo creyendo que hay problemas -incluidos todos los filosóficos- que no se despliegan en la práctica discursiva o científica, sino que se dan en un ámbito distinto, de objeciones posibles, de interlocutores ficticios. Son problemas imaginarios -en el sentido de que no se dan en el mercado o en la oficina- pero no por eso son menos reales, menos apremiantes. Aunque tengamos que parar la discusión sobre el sentido de la vida para no hacernos daño, nos queda la sospecha inquietante de que la vida es absurda y esta duda no puede ser eliminada sin ser reprimida. Lo más práctico es calificarla como confusión y olvidarla. Pero también lo práctico puede ser absurdo. Estar condenado a no poder enfrentar la pregunta del sentido de la vida puede ser la más cruel de las situaciones absurdas.

Sin embargo, está muy lejos de ser un acto de cobardía buscar fallas en los razonamientos que concluyen que la vida es absurda. Voy a considerar dos argumentos que intentan mostrar que hay errores definitivos en el razonamiento que concluye que la vida es absurda; el primero es de corte 
epistemológico; el segundo, de corte lógico. Veamos el primero. Hay quienes han dicho que juzgar la vida como absurda es el resultado de intentar ponerse en una perspectiva externa al acontecer de nuestras propias vidas, como si pudiéramos observar la vida humana, nuestra propia vida, como quien observa un hormiguero, desde lejos, sin involucrarse. Sin embargo, añaden, sólo Dios puede juzgar si la vida humana es absurda, no los hombres que no pueden ver la vida sin meterse de lleno en ella. Es importante percatarse de que este tipo de razonamiento no concluye que la vida tenga sentido, sino que ya que no podemos salir de nuestras vidas para juzgar si son absurdas, no podemos responder la pregunta por el sentido de la vida y por tanto no tiene sentido plantearla. Pero me parece que la conclusión de este argumento es débil e insatisfactoria. Si bien es posible que no podamos responder la pregunta por el sentido de la vida, no podemos olvidarnos de ella, ya que tenemos, para bien o mal, el poder de plantearnos interrogantes sub specie æterni. Por otra parte, no creo que haga falta tener un punto de vista divino para percatarse o para mostrar a los demás que la vida carece de sentido. Los óleos de Brueghel y los textos de Gogol son pruebas de que no hace falta ser Dios para exhibir el absurdo en toda su crudeza. Una es la llamada perspectiva divina —que vería la totalidad del mundo de una manera imparcial y perfecta- y la otra, una perspectiva humana -quizá parcial e imperfecta aunque propia de la sabiduría - que logra darnos una visión de conjunto. Es claro que tenemos que tomar distancia de la vida, de nuestra vida, para preguntarnos por su sentido, pero no es necesario alcanzar alturas divinas para hacerlo.

El segundo argumento en contra de la plausibilidad de la pregunta por el sentido de la vida es más fuerte que el anterior. Este argumento parte de la premisa de que no hay nada que sea intrínsecamente absurdo. Algo es absurdo sólo cuando está en un contexto específico que lo hace tal. En otras palabras, el sentido de algo depende de sus relaciones con otras cosas y no de sus propiedades intrínsecas. Por ejemplo, amarrarse las agujetas no es, en sí mismo, algo con o sin sentido: tiene sentido hacerlo antes de salir a la calle, pero no antes de ser fusilado. Ahora bien, si lo absurdo lo es siempre en un contexto dado que tiene como tela de fondo sucesos que no son absurdos, entonces se podría decir que juzgar la vida como absurda es el resultado de hacer un paso inválido en nuestro razonamiento. La totalidad no puede ser absurda de la misma manera en que algunas partes son absurdas, porque no hay un trasfondo de sentido con que compararla. Decir que la vida es absurda sería algo así como un error categorial. Hay dos tipos de respuestas a la crítica anterior. La primera es sostener que calificamos la vida como absurda basados en la comparación que hacemos de ella con vidas posibles distintas a la nuestra. Sin embargo, el método de 
comparación con vidas posibles tiene ciertas debilidades. Si nuestra vida es absurda en comparación con otras vidas posibles, debemos poder decir algo asi como: esta vida tiene sentido porque $X$ es el caso; o decir: esta otra vida no tiene sentido porque $Y$ es el caso. La tarea, pues, es detectar esas $X \circ Y$ que hipotéticamente le dan o le quitan sentido a una vida posible. Sin embargo, parece que lo que le da y le quita sentido a la vida puede tratarse de lo mismo dependiendo de las circunstancias. Por ejemplo, en un ensayo famoso Bernard Williams ha sostenido que la muerte, en vez de quitarle sentido a la vida, en realidad se lo da. No estoy de acuerdo con Williams, ya que creo que su conclusión es extrapolada de una manera inválida de un caso —el de aburridos seres inmortales- que no tiene nada que ver con nuestra vida. Sin embargo, creo que muestra, aunque ésa no fuera su intención, que no podemos decir si una $X$ o $Y$ le quita o le da sentido a la vida si no la vemos en una red muy compleja.

Otra respuesta que podemos dar a la tesis de que ver la vida como absurda es un error categorial, es decir, que si bien hay una infinidad de sucesos de la vida que no son absurdos, no hay suceso que no sea absurdo cuando se juzga desde un marco de referencia más amplio. Por ejemplo, pasar una noche estudiando para un examen es algo que tiene sentido si se ve en el contexto del proceso de la obtención de un grado. Pero si se ve en un contexto más amplio pierde el sentido que le otorgamos. Es cierto que decir que la vida es absurda es un error categorial. Sin embargo, no lo es decir que todos y cada uno de los sucesos de una vida son absurdos cuando se ven a la distancia. Lo que nos importa no es la vida entendida como algo abstracto, indefinido, sino todo aquello que significa vivir, sucesos concretos, momentos de nuestra existencia. Ahora bien, me parece que cuando decimos que la vida es absurda, lo que en realidad deberíamos decir es que no hay suceso en la vida que no sea absurdo. Y para hacer este juicio no hace falta comparar la vida con una vida posible o asumir un punto de vista divino. Esta conclusión se logra en parte mediante un razonamiento inductivo válido que parte de la observación de que cualquier suceso de nuestra vida pierde su sentido cuando se juzga desde un marco más amplio del que se le atribuye usualmente. Repito, se debe tomar distancia, pero no hace falta salirse del marco.

Casi todos los argumentos que conozco en contra de la plausibilidad de la pregunta por el sentido de la vida se reducen a uno de los anteriores. Pero, si estoy en lo cierto, ninguno logra mostrar que la pregunta por el sentido de la vida sea ociosa o no significativa. El resto del ensayo lo voy a dedicar a elucidar tres distinciones que debemos manejar antes de entrar de lleno en el problema. La primera es la distinción entre lo que llamo el sentido personal de la vida y el sentido trascendental de la misma. La segunda es la 
distinción entre el problema del sentido de la vida y el problema del valor de la misma. La tercera es la distinción que hay entre ver la vida como absurda y verla como un misterio.

La pregunta por el sentido de la vida puede verse como un problema de dimensiones sobrehumanas, pero también puede entenderse de una manera más bien modesta. Un individuo que pasa todo el día bebiendo cerveza y jugando backgammon puede llegar a preguntarse: ¿cuál es el sentido de vivir como vivo? Este individuo puede concluir que la manera en que vive es absurda, sin concluir que la vida misma sea absurda. Una, por tanto, es la pregunta por el sentido de mi vida o de tu vida y otra la pregunta por el sentido de la vida. Por ejemplo, alguien que esté encadenado en un calabozo puede pensar que su vida carece de sentido, pero suponer que lo tendría si estuviera fuera de la celda junto con su familia y en su trabajo. A esto le llamo el problema del sentido personal de la vida. Pero alguien más puede llegar a la conclusión de que su vida nunca tendrá sentido, no importa lo que pase, y que lo mismo sucede con la vida de cualquier otro hombre. A esto le llamo el problema del sentido trascendental de la vida. Me parece que muchas veces no se distingue con claridad entre ambos interrogantes y que esto ha ocasionado más de una confusión, la más común de ellas es pensar que el sentido trascendental de la vida se reduce a su sentido personal.

El prisionero en el calabozo está convencido de que si no hace ciertas cosas o no tiene ciertas cosas a la mano, su vida será absurda. Pero es claro que el prisionero mismo es quien ha escogido lo que le da sentido personal a su vida y, por tanto, sabe que en la celda no puede lograrlo. Casi todos somos como el hombre del calabozo, es decir, nos imponemos propósitos y cuando no los logramos sentimos que nuestra vida ha perdido el sentido que nosotros mismos le hemos dado. Ahora bien, una vida en donde se han agotado las expectativas de satisfacer el sentido que le habíamos asignado es una vida que se puede seguir viviendo e incluso que se puede aprender a disfrutar. Es como si viajáramos a una ciudad para visitar a un amigo y nuestro amigo no estuviera en la ciudad. Al no encontrarlo sentiriamos que nuestro viaje ha perdido su sentido original, pero aun así podríamos seguir viajando con gusto. Lo mismo pasa con un hombre que vive en un calabozo sin ver a nadie. Su vida está reducida a sus funciones orgánicas y lo que sucede en su imaginación. Sin embargo, podría haber quien viviera una vida así sin quejarse demasiado. La mayoría de nosotros, en cambio, vivimos para lograr algo: para tener una casa, para tener una familia, para escribir un libro importante. No hay nada malo en esto. Al contrario, parece que vivir así enriquece nuestra vida, le da una dirección, le da un sentido. Los problemas surgen cuando perdemos la casa, cuando no podemos formar 
una familia, cuando nunca escribimos el libro añorado o incluso cuando, habiendo logrado todo lo buscado, nos quedamos sin metas y caemos en el aburrimiento o en la melancolía. En estos casos no sólo podemos perder el sentido de nuestra vida, sino que podemos llegar a la conclusión de que una vida sin sentido personal es una vida que no vale la pena y considerar seriamente el suicidio.

El sentido personal de la vida está armado por algunos deseos, emociones y valoraciones del sujeto en cuestión. Voy a llamar a aquellos deseos cuya posesión y realización está ligada al sentido personal de la vida deseos básicos. Digamos que un deseo básico es un deseo que orienta una vida. Un deseo es básico en relación con una persona. Lo que para uno es un deseo básico, puede no serlo para otro. Por ejemplo, el deseo de tener hijos es básico para algunas personas, pero no para otras. El deseo de jugar tenis es básico para muchos deportistas, pero no básico para otros. Los deseos básicos dependen de la edad de la persona, por tanto lo que era un deseo básico para alguien puede dejar de serlo de una manera natural con el paso del tiempo. El deseo de jugar futbol puede dejar de ser básico para el futbolista retirado y ser sustituido por otros deseos básicos. El deseo de procrear es básico para una mujer cuando es joven, pero deja de serlo, y sin ningún trauma, cuando entra en la vejez. Es importante darse cuenta de que el sentido personal de la vida depende de los deseos básicos que son naturales a cada edad y a cada persona. Es un error suponer que hay un sentido personal de la vida válido para todas las edades, como si se pudiese hacer abstracción de la edad de un hombre para entender sus motivaciones. Ésta es una de las razones por las que el sentido personal de la vida, como su nombre lo indica, es relativo a la circunstancia de una persona. El sentido personal depende de la edad, el sexo, la comunidad en la que se mueve el sujeto y las creencias y valores que tiene la persona. Nadie puede darnos clases sobre cuál debe ser el sentido personal que le demos a nuestras vidas. Lo único que nos pueden aconsejar es que nuestros deseos básicos vayan de acuerdo con nuestra circunstancia. En cambio, ha habido hombres a lo largo de la historia que han propagado doctrinas del sentido trascendental de la vida que han sido adoptadas por miles de millones de personas. La característica fundamental de estas doctrinas es que valen para cualquiera, sea joven o viejo, rico o pobre, es decir, no dependen de los deseos básicos de las personas que las adoptan -aunque en algunas ocasiones prediquen un cambio en esos deseos básicos.

El sentido personal de la vida no sólo está regido por deseos básicos, sino también por algunas emociones como el amor, el orgullo, la ambición, el odio, la envidia, etc. En la novela de Melville, Moby Dick, el capitán Ahab está poseído por el odio que le tiene a la ballena blanca. El propósito central 
de su vida es matar a la ballena y todo lo demás, ya sea bueno o malo, es secundario. Podríamos dar otros ejemplos de cómo otras emociones y pasiones pueden guiar una vida. Pero me voy a concentrar en el caso del amor, que ocupa un papel muy importante en nuestra cultura. El amor, se ha dicho, puede darle sentido y valor a una vida descarriada. Puede darle sentido, como en el caso de Fausto; puede darle valor, como en el caso de Don Juan. $\mathrm{El}$ amor, más allá de las novelas rosas, más allá del enamoramiento fugaz, es un verdadero misterio. Sin el amor no se entiende el sentido del sacrificio. $Y$ sin el sacrificio no se entiende la esencia del cristianismo. Pero no sólo el amor místico es misterioso. También lo es el hecho cotidiano - pero no por eso menos maravilloso- de amar a alguien, de encontrar un alma gemela. Cuando uno ama lo hace sin razones ni justificaciones. No hacen falta explicaciones para amar, y sin embargo no deja de ser inexplicable amar a una persona. Se pueden dar, claro está, muchas explicaciones del fenómeno; se puede decir, por ejemplo, que todo es un efecto de las hormonas, una jugarreta de la química orgánica. Pero esta explicación ni siquiera toca el misterio, lo pasa de largo a la distancia. La dimensión del amor está entretejida de maneras muy diversas con la cuestión acerca del sentido de la vida. La pérdida del ser amado - lo ha señalado Gabriel Marcel- es perder algo de nuestro propio ser. Es decir, no sólo asistimos a la muerte del ser amado, sino que la experimentamos en lo más íntimo. El problema más doloroso, más preocupante de la muerte, es el de la muerte del otro al que se ama. Es esta muerte la que nos produce más rabia, la que nos incita a esa rebelión contra lo inevitable, que si bien puede parecer una pasión inútil, es en el fondo una de las vetas de nuestra humanidad. Esto no implica, claro está, que la propia muerte nos sea totalmente ajena. Si bien no somos testigos del espectáculo de nuestra propia muerte, sí lo somos de sus preparativos siniestros, es decir, somos los espectadores más cercanos de nuestra propia decadencia. La experiencia del envejecimiento - lo subraya Max Scheleres la experiencia del proceso mismo que nos lleva a nuestro fin. No vivimos nuestra propia muerte, pero sí su antesala.

He sostenido que el sentido personal de la vida está ligado a ciertas emociones y a lo que he llamado deseos básicos. Ahora bien, pareceria que la pregunta acerca del sentido trascendental de la vida tiene que depender de ciertas constantes en la vida de todos los seres humanos. Es decir, si la vida tiene un sentido trascendental, entonces deberá ser el mismo para todos; y si no lo tiene, si la vida es absurda, entonces lo será para todos por igual, no importa su situación, no importa cuál sea el sentido personal que le den a sus vidas. Esto no significa que el sentido trascendental de la vida no pueda estar ligado a la posesión y realización de ciertos deseos básicos, sino que, de estarlo, los deseos básicos en cuestión deben ser comunes a toda 
la humanidad. Cualquiera que sea el sentido trascendental de la vida, éste debe darnos algún tipo de justificación o explicación de tres constantes de la existencia humana que fueron el objeto de la reflexión del Buda, a saber, el sufrimiento, la decadencia y la muerte. Sin embargo, me parece que la explicación de las miserias humanas, por ejemplo, la ofrecida por la religión cristiana, no es equivalente a una explicación del sentido trascendental de la vida. Además de explicar la razón de ser de las miserias humanas, hay que dar la razón de ser de todas y cada una de nuestras vivencias. A fin de distinguir ambos problemas, llamaré al primero el problema del sentido de las mortificaciones, y al segundo le reservaré el nombre del problema del sentido trascendental de la vida. Tengo la impresión de que, cuando la gente habla acerca del sentido de la vida, muchas veces habla sólo del sentido de las mortificaciones, es decir, del sentido del sufrimiento, el envejecimiento y la muerte. Sin embargo, la pregunta por el sentido trascendental de la vida, tal y como yo la veo, es más extensa, ya que abarca la elucidación de la existencia humana en su totalidad. El problema del sentido trascendental de la vida es primordialmente el problema de Kierkegaard, de Sartre, de Heidegger, de Camus e incluso de Cioran. Es el sentimiento de extrañeza aguda que se apodera de nosotros cuando nos detenemos a observar a la distancia el devenir de las cosas humanas. Una mujer cruza corriendo la calle tomando a su hijo de la mano. Suenan las bocinas de los autos. Alguien voltea. La mujer está enojada, maltrata al niño. ¿Por qué tenía que cruzar en ese lugar? ¿Por qué regaña a la criatura? Todo lo humano es cuestionable cuando se observa a la distancia, todo es arbitrario. Entonces nos volvemos extranjeros en el mundo, nos invade la angustia. El universo físico es infinito y hostil, pero no es absurdo. La vida de las plantas es gratuita y sin reposo, pero tampoco es absurda. La vida de los animales salvajes es violenta y difícil, pero tampoco es absurda. Lo absurdo aparece con la vida que se sabe vida y que quiere seguir siendo vida en un mundo sin respuestas. Lo dijo Camus en una frase perfecta: "Labsurde naît de cette confrontation entre l'appel humain et le silence déraisonable du monde."

Tengo la impresión de que la mayoría de las religiones se interesan más en resolver el problema del sentido de las mortificaciones que en responder al problema del sentido trascendental tal y como yo lo entiendo. Quizá no sin razón, ya que el problema de las mortificaciones es el más urgente de la vida humana. Buda contaba la siguiente historia para mostrar a sus discípulos lo absurdo de ocuparse de elucubraciones filosóficas en vez de solucionar el problema de las mortificaciones: un hombre es herido por una flecha en el campo de batalla; cuando sus amigos tratan de extraérsela, pide que no lo curen hasta saber con exactitud cuál es la forma de la flecha, quién la disparó, por qué la disparó, etc. No hay mucho que responder al argumento 
de Buda, pero aun así la solución del problema de las mortificaciones nos puede dejar sin una respuesta a la pregunta por el sentido de la existencia humana. Es más, aceptar la existencia de un Dios creador puede no bastar para responder a la pregunta por el sentido trascendental, y ni siquiera para darle algún sentido a las mortificaciones. Según el Antiguo Testamento, la muerte y la desgracia son justo castigo de Dios. La moraleja del libro de Job, tal como yo lo entiendo, es que, ya que las mortificaciones, así como las bendiciones, vienen todas ellas de Dios, debemos aceptarlas sin pedir razones, con obediencia ciega. Pero esto, al menos para mí que vivo sin esa $\mathrm{fe}$, no me es elucidatorio, e incluso si la tuviera no creo que me sirviera de consuelo. Hay una lectura de la Biblia que puede ver las relaciones de Dios con los hombres como una tragicomedia de venganzas y malentendidos. La creación, desde esta perspectiva, sería una empresa carente de sentido y Dios una víctima más del absurdo.

Quizá hay muy poca gente que considera el problema del sentido trascendental de la vida de una manera personal. Pero aquellos que lo hacen pueden ser orillados al suicidio por la conclusión de que la vida carece de sentido trascendental. Hay quienes creen que podemos tener un sentido personal de la vida, es decir, que podemos ponernos metas y vivir por ellas sin preocuparnos demasiado por un sentido trascendental y que ese sentido personal puede bastar para alejarnos del suicido. Pero cuando la vida se nos derrumba esto puede dejar de ser claro, incluso para el más fuerte. Hay quienes sostienen - Tolstoi es uno de ellos- que es imposible darle un sentido personal a la vida sin tener como base un sentido trascendental que, por así decirlo, ilumine todos y cada uno de nuestros actos y nuestros deseos. Este tipo de pensador afirma que la distinción entre sentido personal y sentido trascendental es, a fin de cuentas, espúrea; que la única manera de dar un sentido personal a una vida como la nuestra, en donde reinan la decadencia y la muerte, es mediante un sentido trascendental. Cualquier otro intento de darle sentido a la vida es fallido, es un espejismo. En contra de esta tesis se puede elaborar un argumento basado en la premisa anteriormente expuesta de que algo tiene sentido sólo en relación con un contexto dado. Si el sentido personal de la vida depende de la realización de ciertos deseos básicos, entonces los sucesos de la vida de alguien pueden tener pleno sentido en el marco delimitado por esos deseos. Pero estos deseos son autosuficientes, es decir, no necesitan de ninguna justificación que los saque del marco en el que se dan naturalmente y, por tanto, las acciones que incitan no tienen que ser juzgadas fuera de ese marco y en consecuencia perder su sentido original. Mientras nos movamos en el marco fijado por nuestros deseos básicos, nuestra vida tendrá sentido personal. El problema, sin embargo, es que es muy difícil que alguien no salga, aunque sea por 
algunos instantes, de ese marco, especialmente si se topa, como es inevitable, con el dolor, la miseria y la muerte. Sin embargo, una vez que, jalados por el mundo, volvemos a la vida diaria, a la vida dictada por los deseos básicos, todo se llega a olvidar, aunque no todo se cure. $Y$ es la necesidad de curarse la que nos hace buscar respuestas trascendentales. Sin embargo, quiero dejar muy claro que las mortificaciones no le quitan necesariamente sentido personal a la vida. Es más, podría decirse que el marco en el que se dan los deseos básicos está trazado por el proceso gradual del envejecimiento y por la certeza de que la muerte nos llegará tarde o temprano. Por tanto, podría decirse que una condición de posibilidad de que tengamos deseos básicos es que envejecemos y morimos. Pero aunque sea cierto que la vida no tendría sentido personal si no hubiera muerte y decadencia, esto no implica - y éste es el meollo de la falacia de Bernard Williams- que la muerte no le reste sentido trascendental a la vida, ya que es posible que nuestra vida tenga sentido personal sin tener sentido trascendental. Para ponerlo en otras palabras: del hecho de que la vida no pueda tener orientación a menos que tenga un marco delimitado, no se sigue que una vida orientada no pueda ser trascendentalmente absurda. La vida infernal de los inmortales - descrita por Borges en uno de sus cuentos- no debe hacernos olvidar lo inaceptable de nuestra situación, de que nosotros y nuestros seres queridos podemos morir en cualquier momento y cuando menos lo queremos. Somos como condenados a muerte que ignoramos el día de la ejecución, y mientras esperamos el llamado del verdugo nos enamoramos, hacemos planes, iniciamos proyectos, etc. Se podría decir que esta incertidumbre es la que nos impide ser indiferentes al presente, al momento vivido; pero también se podría responder que es esta misma situación la que le da un carácter de absurdo a todos nuestros deseos y actos. Especulo: quizá lo mejor para el hombre sería una especie de término medio, no la vida eterna sino la vida indefinida; no estar condenados ni a la inmortalidad ni a la muerte inesperada, sino tener la libertad de vivir y vivir y, cuando así lo escogiéramos, de morir en paz; que hubiera muerte, sí, que hubiera envejecimiento, pero que pudiéramos decirle al verdugo que volviera luego; que fuera posible hacer un pacto de vida con la persona amada para que la muerte no nos la arrebate; que no vivamos de prestado lo que deseamos. En Así hablaba Zaratustra, Nietzsche decía que la alegría quiere la eternidad de todas las cosas. Yo diría, más bien, que la alegría debe querer prolongarse indefinidamente.

Es importante distinguir la pregunta acerca del sentido de la vida de la pregunta acerca del valor de la vida. El que tenga valor hacer algo no implica que tenga sentido hacerlo. Por ejemplo, Kant pensaba que, aunque la moral fuera autónoma, carecía de sentido sin los postulados de la existencia de 
Dios y de la inmortalidad. Por otra parte, es claro que el que tenga sentido hacer algo puede no otorgarle valor. La respuesta a la pregunta por el sentido no requiere necesariamente de un juicio de valor; en cambio, la respuesta a la segunda consiste precisamente en una valoración positiva o negativa de la vida. La pregunta por el valor de la vida es quizá tan o más importante que la pregunta por el sentido de la misma. Alguien que piense que su vida carece de sentido puede descartar el suicidio por suponer que su vida tiene valor. $\mathrm{O}$ al revés, alguien puede desear la muerte por creer que su vida ha perdido su valor, aunque siga teniendo algún tipo de sentido. Sin embargo, no podemos considerar el problema del sentido de la vida sin considerar el del valor de la vida. Los dos van juntos, ya que los dos tienen que ver a fin de cuentas con la pregunta de si la vida vale la pena.

Debemos distinguir entre el valor personal y el valor trascendental de la vida. El valor personal de la vida lo encuentra cada quien en su propia vida. Un hombre deshonrado puede pensar, por ejemplo, que su vida ha perdido su valor, sin pensar que cualquier otra vida lo haya perdido. Por tanto, parece ser que el valor personal de la vida, así como su sentido personal, dependen de factores subjetivos que varían de persona a persona. El valor trascendental de la vida, en cambio, parece valer para todos por igual, no importa el valor personal que le otorguen a sus vidas. Sin embargo, hay un tercer sentido en el que podemos juzgar el valor de una vida que difiere tanto del valor personal como del valor trascendental. Por ejemplo, si se nos preguntara en una circunstancia concreta qué vida vale más, la de Hitler o la de Einstein, tendríamos que juzgar algo distinto del valor personal o el valor trascendental de ambas vidas. Lo que está en juego es un valor que se juzga de manera objetiva, pero que no es trascendental, ya que se juzga de cada individuo en particular. En otras palabras, mientras el valor personal de la vida depende de la valoración que cada sujeto hace de su propia vida, el valor que ahora consideramos -que llamaremos valor objetivo de la vida - no depende de la autovaloración del sujeto, sino de algún criterio que puede ser una combinación de la virtud, la calidad y las consecuencias de las acciones de un sujeto. Es importante que nos demos cuenta de que, si bien el sentido personal de la vida está ligado al valor personal de la vida, no lo está del mismo modo al valor objetivo de la misma. Cuando se condena a alguien a la pena capital, el juez no le está negando valor personal o valor trascendental a la vida del acusado, sino que está reprobando lo que hemos denominado su valor objetivo.

Me parece que la cuestión acerca del sentido personal de la vida está íntimamente ligada a la cuestión acerca del valor personal de la misma, pero creo que sería un error identificarlas sin más. La mayoría de los deseos básicos implican valoraciones positivas. Sin embargo, debemos percatarnos 
de que es posible que las valoraciones que haga el sujeto sean falsas. Por tanto, una vida con sentido y valor personal puede ser una vida sin valor objetivo, aunque sea una vida con una actitud valorativa ante el mundo. Lo anterior es un indicio, uno entre muchos, de la distinción que hay entre el sentido y el valor de la vida. Un hombre que ha logrado todo lo que quería puede sentir que su vida tiene valor, pero que ya no tiene sentido. De la misma manera, un hombre que tiene una vida con sentido puede sentir en algún momento que, a pesar de eso, su vida no tiene valor e incluso que ya no vale la pena vivirse. Pensemos en todos aquellos casos de personas que se suicidan teniendo una vida plena. Además, los deseos básicos de alguien pueden no implicar valoraciones independientes de dichos deseos (es decir, que no sean de la forma: valoro $X$ porque deseo $X$ ) y por tanto puede que el sentido de la vida de alguien no dependa de ninguna valoración objetiva. En alguno de sus libros, Henry Miller decía que lo que más le importaba en la vida eran el sexo y la comida (no recuerdo si en ese orden). Una vida así - vaya que las hay - estaría regida por apetitos que no implican valoraciones independientes de dichos gustos y, por tanto, el sentido de la vida de alguien así no tendría un trasfondo valorativo objetivo. Me parece que el trabajo filosófico más indispensable -y a la vez más accesiblecon respecto al problema del sentido de la vida se encuentra en el estudio detallado, caso por caso, de la relación que hay entre las distintas respuestas que se puedan dar al sentido de la vida y la naturaleza y forma de nuestras acciones, deseos básicos, valoraciones, valores y emociones. Sin embargo, la pregunta filosófica más importante, aunque especulativa y difícil, es la que tiene que ver con el valor trascendental de la vida.

Una vida puede tener valor personal y luego perderlo. Un hombre que se siente deshonrado hasta el tuétano puede sentir que su muerte es mejor que una vida indigna. Un hombre que se encuentra en una cama de hospital muriéndose lentamente, sin parientes ni amigos, puede también llegar a la conclusión de que es preferible terminar su vida antes que prolongar una agonía dolorosa y humillante. En cambio, los que consideran que la vida no tiene valor trascendental están comprometidos con la tesis de que el universo no perdería nada si dejara de haber vida. Por ejemplo, Bertrand Russell llegó a sostener que el hecho de que haya o no vida en el universo es intrascendente desde un punto de vista cósmico. La vida humana, para Russell, es una nota a pie de página en la historia de la galaxia, un suceso insignificante en el universo. Pero hay una postura todavia más fuerte que sostiene que un universo sin vida humana sería mejor que uno con ella. Tal es la postura del mítico Sileno, que, según cuenta la leyenda, le dijo al rey Midas que lo mejor para un hombre es no haber nacido, pero ya que ha nacido lo mejor para él es morir pronto. No creo que haya pesimismo más 
duro que el de Sileno, que no ve en la muerte el problema sino el remedio. Otra postura que concluye que la vida no vale nada - aunque por razones distintas - es la de Schopenhauer, quien pensaba que la decadencia y la muerte no sólo le restan sentido a la vida, sino le quitan todo su valor. Para Schopenhauer la vida es una farsa grotesta y patética; $y$ la muerte, nos dice, la prueba definitiva de que el camino de la vida es un camino errado. En la obra de Samuel Beckett, Happy Days, una mujer enterrada en la arena hasta la cintura ve pasar los dias y las noches pensando en nimiedades mientras se hunde lentamente dentro de la tierra. Una vida así, diría Schopenhauer, diría cualquiera, no vale nada porque la agonía y la esclavitud hacen de todas nuestras alegrías espejismos y de todos nuestros deseos fantasías. Pero ¿acaso no nos hundimos en la arena mientras comemos pepitas o leemos el periódico? ¿Acaso somos libres de cambiar nuestra situación, de rebelarnos contra las mortificaciones de la vida?

Hemos sugerido que es posible que la vida tenga sentido personal sin sentido trascendental. En este momento de la discusión nos topamos con tres preguntas de importancia definitiva. La primera es: ¿puede tener valor trascendental una vida sin sentido trascendental? La segunda es: ¿puede tener sentido trascendental una vida sin valor trascendental? Y la tercera es: ¿puede tener algún valor una vida sin valor trascendental? Debo confesar que ignoro las respuestas a estas preguntas, y es aquí donde me planteo la necesidad de iniciar un nuevo ensayo. Por una parte, no sé cómo podríamos saber a ciencia cierta si la vida tiene o no valor trascendental. Por otra parte, tampoco sé cómo podamos juzgar objetivamente si nuestra vida tiene valor. A veces tengo la impresión de que el valor de mi vida, como el de cualquier otra, es una evidencia, es decir, algo donde no hay posibilidad de error. Otras veces pienso que es posible que vivamos en un autoengaño, que le demos a nuestras vidas un valor que en realidad no poseen ni pueden poseer. Es decir, puede ser que el valor personal de la vida no dependa en lo absoluto del valor objetivo o del valor trascendental de la vida. ¿Pero tiene sentido aferrarse a una vida sin valor trascendental? Parece que para alguien como Unamuno el deseo de no morir no depende del valor ni del sentido de la vida, sino tan sólo del hecho natural de que nos aferramos a nuestro propio ser. Más que el deseo de vivir, lo que tenemos -desde esta perspectiva- es el deseo intenso de no morir. Pero el connato humano puede ser el más grande de los absurdos. Sin embargo, podemos volver a preguntar ¿absurdo para quién? Para el hombre que se aferra a la vida no hay tal absurdo y no le importa lo que piensen los otros. De lo que sí estoy convencido es de que no hay un criterio objetivo que nos diga cuándo una vida vale la pena vivirse y cuándo no. Es decir, no creo que haya un criterio que nos diga cuándo alguien se suicida con razón. A diferencia del sentido 
personal de la vida, el valor personal de la misma es algo más difícil de evaluar de una manera imparcial. Nuestra creencia de que nuestra propia vida vale la pena vivirse está colgada de una convicción casi visceral, pero podría ser falsa, podría ser un fantasma. Pero lo que más me preocupa es la posibilidad de que la vida pueda tener sentido personal sin tener valor. Es decir, que la realización plena de nuestros deseos básicos no le dé valor a la vida. Una vida feliz puede ser una vida que, juzgada desde un punto de vista objetivo, no valga la pena vivirse, es más, puede ser una vida repugnante. Pero caigo otra vez en lo mismo: quizá es un error juzgar el valor de mi vida o de tu vida con base en consideraciones que no sean estrictamente subjetivas. Si somos felices nadie puede convencernos, sin violencia, de que carece de valor. Kierkegaard sostenía que es un error tomar la vida de una manera que no sea absolutamente subjetiva. De estar en lo cierto, el valor que le demos a nuestras vidas es lo único que debe importarnos; y sean cuales sean las conclusiones a las que llegue la razón especulativa con respecto a su valor trascendental, sean cuales sean las conclusiones acerca del valor objetivo a las que lleguen los otros, es algo que no debemos tomar en cuenta, que no debe amargarnos. Esta solución es la más fácil, la que más me gusta. Pero todavía no estoy seguro de que sea la correcta.

Queda por tratar, aunque sea velozmente, el problema de si una vida absurda puede ser una vida con valor. A primera vista parece que sí puede, ya que son ámbitos distintos. Un acto puede tener valor sin tener sentido. Pero cuando es toda la vida la que está en juego, deja de ser obvio que la falta de sentido no implique también la falta de valor. Camus sostiene que, si bien la vida es absurda, no es despreciable, es decir, tiene valor y, por tanto, es racional no suicidarse. El valor que parece otorgarle Camus a la vida es el de la dignidad de sobrellevar el absurdo. Más allá de nuestro acuerdo o desacuerdo con Camus, es importante percatarse de que su propuesta está basada en la hipótesis - que precisamente hemos puesto en duda- de que el sentido de la vida no determina su valor. Una solución alternativa es que podemos vivir bien una vida trascendentalmente absurda. Hay quienes han descrito la vida absurda como una vida que puede ser graciosa y a la vez amable. Tal es el caso de Ionesco, que en sus obras se ríe del absurdo sin pintar la vida como un infierno. También podemos recordar el caso de algunos surrealistas - tengo en mente a Luis Buñuel - que nos mostraron que una vida absurda puede ser una vida divertida, una vida en donde se pueden hacer travesuras como abofetear un cadáver o jalarle las barbas a un director de orquesta. Sin embargo, me parece que este humor sólo es posible con el telón de fondo de una percepción moral del mundo. Lo absurdo se puede tomar con buen humor porque se tiene la tranquilidad de que la vida no es un desierto axiológico, de otra manera se convierte 
en una broma macabra. El humor negro expone el absurdo de una manera violenta y a la vez increíblemente lejana. Este tipo de humor -como diría Kierkegaard- es, a fin de cuentas, un lamento disfrazado.

Para terminar, quisiera decir algo sobre lo que para algunos es el trasfondo luminoso del absurdo. He sostenido que la pregunta por el sentido trascendental de la vida, de tener respuesta, debe ser algún tipo de principio unificador, de fórmula universal, en el cual caigan todas nuestras vivencias. Sin embargo, no me queda claro en qué forma deba estar expresado este principio. Quizá más que una explicación, lo que se requiera sea algún tipo de iluminación, es decir, un estado que no se logra leyendo un libro o escribiendo un ensayo, sino que sea el resultado de una vivencia reveladora. Conviene que exploremos esta posibilidad aunque rebase el campo de la filosofía analítica en donde me he movido. El carácter esencialmente vivencial, no conceptual, de la iluminación está en el fondo de la inefabilidad de la experiencia mística. Por esta razón se ha sostenido que no puede haber manuales ni escuelas de iluminación. Por ejemplo, los textos de budismo Zen están atiborrados de historias curiosas de cómo se adquiere la iluminación mediante acontecimientos triviales. Basta con que narremos una. Un alumno visita a su maestro y le pide que le revele el sentido de la vida. El maestro, que se encuentra al fondo de una habitación oscura, le ordena al alumno que se acerque a su lado y que prenda una vela para guiarse. Cuando el alumno llega junto al maestro, éste apaga la vela con un fuerte soplido y es entonces cuando el alumno encuentra el camino. Estas historias no nos dicen en qué consiste el sentido de la vida, claro está, pero sí nos indican que no vamos a encontrarlo por un medio racional o discursivo. Quizá no hay una pregunta acerca del sentido trascendental de la vida y, por tanto, no haya respuesta satisfactoria. Quizá, en vez de un problema sobre el cual podemos hacer preguntas y respuestas, nos encontramos frente a un misterio que no permite ni las unas ni las otras. Hablar del misterio no debe tomarse como una alusión al más allá. Hay quienes buscan el misterio en lo inasible, en lo extraodinario. Otros, en cambio, lo encuentran - a veces sin buscarlo- en lo más familiar, en lo más cercano. Es este misterio el que tiene que ver con lo que estamos hablando. Quizá la pregunta por el sentido de la vida, en su expresión más profunda, nace del enfrentamiento del hombre con el misterio de lo cotidiano. Y el misterio no es lo mismo que lo absurdo. Se nos podría recordar que acerca del misterio no se puede hablar y que acerca de lo que no se puede hablar lo mejor es callarse. Es cierto. Pero la condición humana es no poder dejar de balbucear acerca de lo inefable; tenemos que llenar con palabras el silencio para no perder la cordura. Pero esto no significa que haya respuestas entre las palabras. El misterio no se explica ni se entiende, se nos revela y punto. Y ni siquiera hace falta so- 
lucionar el enigma. Presenciarlo basta para calmar el alma. Hay un pasaje de La guerra y la paz que ilustra la posibilidad anterior. El príncipe Andrés Volkonsky - nos cuenta Tolstoi- yace en su lecho de muerte acompañado por las dos mujeres que más lo aman en el mundo: su hermana, la princesa María y su prometida, Natalia Rostova. La agonía del príncipe Andrés se ha prolongado por varios días y tanto María como Natalia han estado a su lado todo el tiempo. Ambas saben que Andrés va a morir y, sin embargo, no muestran signos de dolor o desesperación. Por fin, Andrés deja de existir. Natalia se acerca al cuerpo inmóvil de su amado, le cierra los ojos y entonces se pregunta sin recibir respuesta: ¿Dónde se ha ido? ¿Dónde está él ahora? El cuerpo frío del príncipe es preparado para el sepelio y depositado en un féretro abierto. Es entonces cuando sus deudos lloran desconsolados. El hijo del príncipe, el pequeño Nicolás, llora al sentir su corazón invadido por una perplejidad dolorosa. La madre de Natalia llora de lástima por su hija y por la ausencia del príncipe. El padre de Natalia llora porque sabe que él también deberá morir algún día. En cambio —escribe Tolstoi- Natalia y María no lloran de dolor, sino que lloran presas de una emoción que se ha aposentado en sus almas ante la presencia del misterio de la muerte. ¿Qué podemos aprender de la narración? Natalia y María ya no tienen necesidad de recibir respuestas. Su alma está invadida por una emoción distinta a la del dolor o a la del miedo, por una emoción que Tolstoi califica como reverente. En esos momentos, únicos y plenos, los interrogantes sobran, los problemas se acaban. De haber tenido una experiencia así, creo que no hubiera escrito este ensayo... pero su muerte sólo me dejó perplejidad y desgarramiento. 